STRATEGIC INITIATIVES DURING MERGER BETWEEN EMIRATES BANK
INTERNATIONAL (EBI) AND NATIONAL
BANK OF DUBAI (NBD)

\author{
* Beena SALIM \\ *Skyline University College, United Arab Emirates
}

\begin{abstract}
The present study focuses on the merger between two banking giants Emirates Bank and NBD. The study first focuses on the reasons behind this merger to give a background information and then move forwards to identify the major strategic initiatives that the merged companies had to do to make the merger happen with less number of difficulties and to reap the benefits of the merger in the business environment. When mergers take place between two firms in the same industry we call it as horizontal merger. Krishnan and park( 2002) have observed that mergers commonly take place horizontally and mostly between direct competitors. Studies have proven that majority of the merger and acquisition activity lead to failures, with failure rates between 60 to $80 \%$ (Marks and Mirvis 2001; Tetenbaum 1999). Hence it will be interesting analyze the strategic initiatives used by Emirates NBD in making their merger a success story. The study found that they had initiated a proactive change management plan, workshops, human deployment decisions, system integration decisions and finally rebranding to make their story a success. Early decisions related to human resource, Leadership involvement, Task integration, Employee engagement, system integration, customer integration and rebranding were the key areas that they concentrated in the change process.
\end{abstract}

Key words- Merger, task integration, human integration, rebranding, employee engagement, speed of change, extent of change.

\title{
INTRODUCTION
}

Merger is the activity by which two or more companies decide to come together and function as one for achieving strategic objectives or goals like resource sharing, resource utilization, economies of scale achievement or cost minimization or any other operational or financial advantage for both the companies. The post merger activities have gained increased attention as researchers have shown that all of value creation happens after acquisition or merger (Haspeslagh and Jemison (1991, p. 129). The topics of post merger integration have also received increasing attention from researchers (Capron, Dussauge, and Mitchell 1998; Datta 1991; Larsson and Finkelstein 1999; Shrivastava 1986). Chatterjee and colleagues (1992) examined the impact of "cultural fit" between the target and acquirer in a sample of mergers. Their results showed that mergers in which there was a match between the target and bidder on dimensions such as risk-taking attitude, reward orientation, innovation orientation, and autonomy orientation resulted in superior stockholder gains and that those that involved cultural mismatches did not perform as well. In a study conducted along similar lines, Datta and colleagues (1991) examined the performance impact of incompatibility in the management styles of acquirer and target firms. They found that inconsistency between the management teams of acquirer and target on factors such as decision-making approach, risk propensity, and time orientation was negatively related to post merger performance. The study looks into the merger integration activities of Emirates NBD and learn from the challenges and opportunities of the merger.

On March 6, 2007, Emirates Bank International (EBI) and National Bank of Dubai (NBD) announced a government approved merger creating one of the Middle East's largest bank with assets of more than US\$ 55 billion, surpassing the country's biggest lender - National Bank of Abu Dhabi. Aimed at enabling UAE to compete in global markets in the face of its predicted Free Trade Agreements (FTA) 
with the US and other countries as well as the World Trade Organization membership the merger complements EBI's strong brand image and a large retail presence with NBD's edge in corporate banking. Besides providing the merged entity the size of assets and funds comparable to international banks, it could provide reach by way of increased number of branches, broader customer base and even a pool of internal staff talents that can meet increased demands in a short time (Gulf Today, May 8, 2007 from Mitra and Pandey, 2008).

\section{Need for the study}

As Marks and Philip (2001) point out in their research paper, it is very difficult to understand the merger activities as in many cases there is very less cooperation towards a research program when the merger activity is going on. Hence many of the merger studies happen in retrospective fashion. In many cases therefore there is a loss of many important learning that could have been useful for the academia and industry. Up till now there is no recorded study of strategic initiatives or activities of merger in the region and hence this research may bring facets of merger factors that may help to add to the existing knowledge for the region as well as for companies who hope to do merger with companies in this region. This study may throw some lights into importance of strategic integration of merger activities with focus on task and human integration.

In a merger often executives are confused and employees anxious as to what will happen to them and no one would show an interest in cooperating for a research program. But a banking organization like Emirates NBD which speaks about its financial success after their merger may be a much better target to understand the behind the merger activities that lead to the success.

\section{Relevant theories}

The resource based firm theory is perhaps the most important theory that looks into why firms go for mergers or acquisitions. The theory states that firm's effectiveness is usually measured based on the superior performance by specific resources owned by the firm. Barney (1991) defines these resources as the specific assets, firm attributes, organizational processes, capabilities, information, knowledge etc. The present study also would like to follow this definition of resources that create a competitive advantage for firms.

These resources enable organizations to create strategies for superior performance and hence need to have four specific attributes- rarity, imperfect imitability, value and in substitutability. This resource is mostly the reason why firms go for acquisition or merger as it is very difficult to get these resources in parts and hence they go for whole acquisition (Anand and Singh, 1997; Karim and Mitchell 2000).

But after a merger or acquisition in most cases it is the integration of these existing capabilities and resources between each of these firms that contribute to the success of the M \& A. The important areas where integration is important are integration of $\mathrm{R} \& \mathrm{D}$, manufacturing, marketing and sales, and managerial, financial and senior executive resources. Since the study is on services sector there is greater need to look into managerial, senior executives, financial, internal processes, and marketing resource integration which affected the humane and task integration of the organization.

Extent of integration required can directly affect the time taken and cost savings for the integration activity. If the differences between the two firms were too large then time taken and cost will be high. If the extent of integration can be brought down by adapting processes and systems of one firm then it will be much easier, but sometimes the resistance from the other firm could be too high too. This extent of integration can be reduced by taking the best of both worlds in integration process. According to Birkinshaw , Bestman and Hackenson (2000) extent of integration is an important predictor of firm performance after an acquisition. Mitchell (1989) and Bragado (1992) have highlighted the importance of speed of integration in mergers. Integration is much easier when there is similarity among firms and there is an impact on post merger performance of the firm ( Ramaswamy, 1997)

Research on acquisitions and mergers can be seen from four important perspectives- financial economics, strategic management, organization behavior and processes. Financial economics objective is to enhance wealth for the general economy and shareholders. The theoretical background 
of this is the agency theory (Manne,1965). Acquisitions enhances the ability of corporate for market control and thus result in wealth creation for the shareholders. Strategic management perspective focus will be to improve the performance of acquired or merged company which comes through synergies of economies of scale, market power, and market that will create better performance. Barney (1988) says that this come only through resource based view of the firm where firms which can integrate or harness the power of resource integration will have better performance in the market. Third is the human and cultural integration of the two organizations which comes from congruence of cultures or effective acculturalization which will lead to improved employee satisfaction and integration. Final is the process perspective which comes from the behavioral theory of firm which points out the importance of actions of management and process of integration that determines the benefits of integration for the firms (Cyert and March, 1963). Many structural and organizational variables can affect firm performance after merger or acquisition (Chatterjee, 1992). These include market share, relative size, pre-acquisition, experience, timing relative to the business cycle, and business relatedness . Barney (1988) challenged the internal operations perspective and suggested that these synergistic benefits may be reflected in acquisition pricing. Research relating to strategic and organizational fit to performance is consistent with this hypothesis (Datta, 1991). In this regard, this research also embraced some of the concerns of organizational behaviour scholars who study corporate acquisitions

Out of these four the process perspective, human and cultural integration, and organization behavior which relates in the way management activates the merger is important as it focuses on important actions and the human behavior and reactions that may lead to success or failure of a merger.

The study hence propose that there should be deeper investigation on these perspectives to understand more about acquisition and merger success or failures. Haspeslagh and Jemison (1991, p. 180), for example, talk about the need to 'alleviate concerns by carefully communicating and con-firming what will not change to the managers and employees of the acquired firm before any attempts are made to combine the two organizations. In some cases Task integration is given more emphasis and then human integration, but the ideal situation is a balance between task and human integration.

An emphasis on human integration may lead to satisfied employees, but no task synergies. The study will analyze the important strategic initiatives related to employee engagement processes, the merged organization took immediately after the merger decision and how it faced the challenges of integrating the other core resource integration for success of the firm. We can define integration as to the extent to which both firms tried to match their managerial, senior executive capabilities and their financial, internal processes, and marketing resources. For this first we need to understand what were the key differences between the firms in the above resources where integration was necessary. Hence it is important to analyze the differences between, structure, system and processes. Differences in their product, service strategy, branding strategy, sales channels etc were important as the firm is in services sector. Objective of the integration become key in deciding the outcomes of the integration activities.

\section{Research questions}

1. What actions were taken by management to ensure that operational activities are in synergy in the merged organization? How did they achieve operational efficiency and effectiveness?

2. How did they manage the duplicity of departments and hence the operational process duplicity, from both the organizations. What were the strategies used?

3. What actions were taken over time to manage the human integration process and what were the outcomes?

4. How did they achieve human engagement in the merger process

5. Was there a dominance of task integration or human integration in driving the success of the merger? 


\section{Objective of the study:}

The main objective of the study is to understand the type of activities that were implemented by Emirates NBD merger in the region. This will be tied to success measures like Revenue or ROI figures published during the merger transition period. UAE being a much observed economy by many other international players, it is important to analyze and understand the post merger behavior in the region.

A case study in most cases is a more tacit knowledge sharing platform and can be useful for future researchers and practitioners in understanding merger behaviors in the region. Mistakes and challenges are part of the post merger transition period which can be an eye opener for others in tested in the same activity.

\section{METHODOLOGY}

Case study method is used for the research paper. Since the subject is "merger" and as there are many activities that happen differently with different organizations during a merger, common survey or questionnaire method would not yield the real perspective of the study. Hence face to face individual sessions and schedules are used to collect the data related to merger based on previous constructs of merger literature where human and task integration are the predominant ones. Data is collected from strategic change management team, and GM of strategic management. Data collection was done using a schedule for interviewing key strategic and change management personnel in the organization. Interviews were done with open questions in which the respondent is asked to tell the story behind the merger, its success and difficulties. The GM of strategy in Emirates NBD was interviewed for the merger story.

\section{Company- Emirates Bank and NBD}

The merger between Emirates international Bank and NBD was announced on March $6^{\text {th }} 2007$ which was a merger between the number 2 ( EIB) and number 4 (NBD) bank in UAE and the objective was to create the largest bank with asset maximization. This was done to ensure that investment from foreign countries as well as for domestic purposes could be done through a bank which has credibility in the region. There was immense growth during 2007. But end of 2008 recession hit the world and the bank had to do a change in their strategy. The merger was done during a period where the banks and the government was seeing leaps of growth in real estate as well as in other investments in the region and across the world.

The new target business model was defined and planned after the legal closing of the integration initiatives. There were consultants to do the human integration of the process and the bank did run the highest number of cultural integration workshops for their employees through and external change management consultancy. The integration was completed and handed over to the line management by the end of 2009.

\section{Vision and Mission}

The first important step in the integration was to decide on one vision and mission for the merged entities. This was done through several work shops with senior management of both the companies. The new mission statement - Emirates NBD provides innovative financial products and services to fulfill the financial goals of the customers through out the world. The motto was "We win and keep stakeholder trust by : delivering a personal and superior customer experience, offering an exciting place to work that encourages career development and rewards superior performance, contributing to the growth and prosperity of UAE region, and creating consistent, exceptional, long term shareholder value". The new values were - Our values are - customer centric, enables differentiation with service excellence and innovation and builds on our people- integrity, passion for performance and Teamwork. 


\section{Human integration}

The merger human strategy was to have an early and quick decision about employees at an early stage. Although decisions related to employees are always tough it was important for the bank to make it as early as possible They did it with the human resource teams of both the organizations. The bank did do their best to retain the best talent.

In the first instance itself it was announced that there will be no downsizing or layoffs to ensure that employees are not affected in a negative way by the merger. An integration team was formed which acted as a driver for the overall process of merger. There was a road map, clear and detailed work plan, set top down targets, set high targets and early executive alignment, measure and review the process regularly, communicated updates and ensured that business momentum was maintained.

Early executive alignment was important for the merged organization. The chairman and CEO of Emirates Bank International(EIB) remained after the first phase of integration, and most of the top management team of EIB stayed to support their leaders. Rick Pudiner became the CEO of the merged organization. As in many merger one organization leadership will predominate in the final merged entity. The integration team thus headed by this leadership ensured to create a new vision, mission and values and guiding principles for the Emirates NBD entity. The redefined vision is, " To be Globally recognized as a leading and most dynamic financial services provider based in middle east".

They did 107 culture integration workshops to bring together the employees and share with them the new vision, mission and values. The employees in the initial stage did have hostility although covered to their counterparts. They did face the anxieties where their fellow employees were leaving the organization. Some were satisfied with the change when it gave them better roles to play in the merged organization. Although new culture and values were made, the espoused values of the current leaders and employees will always reflect in the organization. As such we can say that there would be more Emirates International Bank way of doing things in the merged organization. This culture would have slowly changed into the existing level after the culture workshops and activities. The GM strategy says that they have tried to bring in the best of both worlds into the new organization.

\section{Task Integration and Rebranding}

HR and marketing department worked along with the integration team in formulating and consolidating new HR plans, policies, structure and marketing strategies for the organization. Along with these departments IT, Audit, finance, and risk management departments also did a very good task in integration.

During the first phase of integration operations of the two banks continued separately as the bank did not want to disturb the customer operations in any way. The two banks had different operating systems for customer operations. They had to integrate the same on to one system. Slowly in a planned way they moved the operations with the help of the employees into one single system which is the finnnacle system.

As the integration proceeded and after the legal closing of the deal, the recession already hit the market (by end of 2008) and the merged entity had to revamp their initial strategies and hence the organization structure. During this period a new structure was again formulated and organization was ensuring that an integration team was doing their best to ensure smooth day to day operations.

\section{Operational or Task Integration}

The integration team along with change management consultancy Genesis focused on communicating the change plans and initiatives across the organization. The strategy GM of Emirates NBD agreed that there were many employee concerns, and anxieties that had to be tackled during the merger. They did run 107 workshops for employee integration and buy in for the merger. Eventually some employee attrition did happen and the exact percentage could not be got as it was not revealed to the researcher. Careful profile analysis and performance report analysis were used in changing employee positions and giving them new positions in the merged company. Some employees were unhappy with the new 
arrangement and hence chose to move out on their own. The researcher was informed that as in any merger there was the "us and them" feeling among the employees in the organization. But it just went away gradually as process integration and operations integration started.

The employees had to divide part of their daily work time for the process integration activities whereby the organization had to meet the milestones of integration. At the same time they had to serve customers upfront without creating any disturbance to customer services.

First level of integration for tasks was done in the following steps. The major milestones in these were - $16^{\text {th }}$ October 2007- Emirates NBD making its debut on Dubai stock exchange. April 292008 Successful integration of 92 ATMs, $9^{\text {th }}$ july- first staff move to Al Barsha- new IT and operations processing center, $14^{\text {th }}$ July 2008- Integration of ATMs completed, $27^{\text {th }}$ August 2008- Integration of 107 workshops completed with 5000 employees, $11^{\text {th }}$ august 2008 - mobile and online banking integrated.

The major mile stone in the second phase was IT integration I, II and then rebranding which happened in 2009. Core banking roll out and system migration for EBI happened on May 9 2009. Oracle system roll out to NBD was done on $4^{\text {th }}$ October 2009 and on $10^{\text {th }}$ October 2009 there was Finnacle roll out to NBD. By November 2009 Emirates NBD started operating on single system, From November 2009 to Jabuary 2010 there was rebranding across all branches.

The merged Emirates NBD stood at a higher ranking of $4^{\text {th }}$ in the region with an increase of $19 \%$ revenue growth in the year 2007-2008 inspite of changes caused due to merger. In 2011 report they stand next to Abudhabhi National bank. Their strategic focus is now more into retail operations with future orientation towards corporate operations. They still do have corporate operations. They are the number one bank in the region with $\$ 76.8$ billion assest, $\$ 8.5 \mathrm{~B}$ equity and $\$ 575$ million in net profits as of June 2009.

\section{Stakeholder Management}

Customers, employees and other stakeholders of the merged entity were given attention and the integration team did give importance in communicating to them about latest developments that can affect them in any way. There was high emphasis on internal communications as everybody need to be involved in the loop of latest changes and developments. Customers started using the consolidated or merged systems and operations by the end of 2009 and they saw the banks as one after the new rebranding done for the bank.

\section{Leadership Involvement in change}

The CEO and chairman always tried to be present in the workshops where they communicated to employees about new developments and changes. The presence of CEO always made a difference to these workshops. There could have been more of CEO and top management participation was the comment from the strategic integration team of the bank.

\section{Duplicity of process and work}

The employees did their own bank operations till they entered into the roll out of the new system. Hence for some time there was duplicity of the tasks at the operations level. This strategy was used not to disturb any customer related operations and create problems for customers. But the synergies of the other important teams from both banks were well utilized through out the transition. The organization utilized the expertise and competencies of HR, Finance, audit, IT and risk management teams and their synergy to make the integration a success.

\section{Employee Engagement}

This was an important part of the transition process. Culture workshops alone was not sufficient to gain employee engagement. They did employee engagement practices within the organization. Line managers were incorporated into the programs where performance targets and performance evaluation were done on a continual basis to ensure employee engagement in all activities of integration. This 
process oriented focus into their work activities, which kept the employees engaged in their activities and provided support for the change initiatives. The employees were engaged in their daily operations as well as in integration activities using ongoing performance review meetings and plan of actions.

An external employee satisfaction and engagement survey conducted did prove that the merged organization had a score which was not very much below from the benchmarked level. Hence the company did take their human integration seriously and ensured that proactive plans were chalked out and implemented for the success of the merger.

\section{CONCLUSION}

The merger success story of Emirates NBD clearly supports the theories and research of many of the researchers given in the theories section of this article. The merger was a carefully planned initiative between two banks who wanted to capitalize on their resource synergies and become the biggest bank in the region. The story is interesting as the decision was done when the economy was booming not only in UAE, but the rest of the world. Hence the beginning of the merger was driven by expansion plans for the entity where both banks would utilize the best of their strategic strengths for the advantage of the other and make a truly winning story. But economic crisis in the form of recession did affect the initial plans, strategies as well as structure which indirectly affected the human resource plans. But the organization did utilize the best of consultants and proactively planned new strategies for integration and could successfully implement their task and human integration making it a success story for the region. They achieved the financial targets also in the process. The story also highlighted that in mergers one of the companies would predominate after the initial phase and the decision makers of this organization further takes the merged company to a new level of success based on their strategic initiatives. Employee movement is an inevitable part of any merger and as this merger and many of the previous studies point out there should be speed in decision making related to employees and their roles. This can reduce ambiguity as early as possible although it can be hard decisions. Emirates NBD story proves that human integration speed should be fast and then proactive task integration need to be done for the success of a merger. The extent of integration is less in this merger as it was two entities of similar kind doing similar operations. There was only system integration at an operation level to be done in the merged entity.

Findings: The study found that the most important activities in a merger is to have a proactive plan for change, decide on the leadership teams guiding the change, implement quick manpower decisions, and decide on what tasks and operations need to be aligned. Human integration decisions are important and should be done very quickly and further management of change should be done using numerous face to face communication sessions for effective transfer of change plans and initiatives. This can reduce the anxiety and stress among employees and prepare them for changes.

Another important finding of the study that is in line with previous research is that strategic changes can be done through employee engagement. It is important to have line managers who engage the workers in the change initiatives through weekly meetings and have targets for the employees. The creation of common mission, vision and objectives through human integration and change workshops worked perfectly well for Emirates NBD to move the people from us and them feeling to the we feeling. Re- branding was another area that was done with care in the case. The most important thing was that customers were not affected in a negative manner as system alignment task was completed and then the customers were informed about the same with rebranding techniques. Speed and extent of change in merger can have an effect on merger success stories. In this case there was speed of change. Leadership plays an important part in determining the success of the merger. Another important point is proactive planning of all merger related human and cultural as well as process changes. But the variable of extent of change is low as the merger was a horizontal merger. The banks did successfully integrate their capabilities and resources to create a merged successful entity for the region. 


\section{Future studies and recommendations}

Researchers can further look into more mergers in the region and do an empirical study to prove the hypothesis that speed of merger is very important in horizontal mergers. Strategic initiatives mentioned in this case study can be further analyzed across different merger cases for an empirical analysis.

The study could not probe much into employee satisfaction or dissatisfaction levels as in any mergers the organization was not open for such a scrutiny. But future researchers can look into how organizations overcome this dissatisfaction with effective engagement processes.

As this is a case study it cannot be generalized across for all mergers. 


\section{REFERNECES}

Anand, Jaideep and Harbir Singh (1997), “Asset Redeployment, Acquisitions and Corporate Strategy in Declining Industries,” Strategic Management Journal, 18 (Summer Special Issue), 99-118.

Barney, Jay B. (1991), "Firm Resources and Sustained Competitive Advantage," Journal of Management, 17 (1), 99-120. "Strategic Factor Markets: Expectations, Luck, and Business Strategy," Management Science, 42 (10), 1231-41.

Barney, J. 1988. Returns to bidding firms in mergers and acquisitions: Reconsidering the relatedness hypothesis. Strategic Management. J. 9 71-78.

Birkinshaw, Julian, Allen Morrison, and John Hulland (1995), "Structural and Competitive Determinants of a Global Integration Strategy," Strategic Management Journal, 16 (8), 637-55.

Birkinshaw, Julian, Henrik Bresman, and Lars Hakanson (2000), "Managing the Post-Acquisition Integration Process: How the Human Integration and Task Integration Processes Interact to Foster Value Creation,” Journal of Management Studies, 37 (3), 395-425.

Bragado, Julio F. (1992), “Setting the Correct Speed for Post- Merger Integration,” M\&A Europe, 5 (March/April), 24-31.

Capron, Laurence (1999), “The Long-Term Performance of Horizontal Acquisitions," Strategic Management Journal, 20 (11), 987-1018.

Capron, Laurence and John Hulland (1999), "Redeployment of Brands, Sales Forces, and General Marketing Management Expertise Following Horizontal Acquisitions: A Resource-Based View," Journal of Marketing, 63 (April), 41-54.

Capron, Laurence, Pierre Dussauge, and Will Mitchell (1998), "Resource Redeployment Following Horizontal Acquisitions in Europe and North America, 1988-1992," Strategic Management Journal, 19 (7), 631-61.

Chatterjee, S. 1986. Types of synergy and economic value: The impact of acquisitions on merging and rival firms. Strategic Management Journal, 7: 119-139.

Chatterjee, S., Lubatkin, M. H., Schweiger, D. M., \& Weber, Y. 1992. Cultural differences and shareholder value in related mergers: Linking equity and buman capital. Strategic Management Journal, 13: 319-334.

Datta, Deepak K. (1991), "Organizational Fit and Acquisition Performance: Effects of PostAcquisition Integration,” Strategic Management Journal, 12 (4), 281-97

Haspeslagh, Philippe C. and David B. Jemison (1991), Managing Acquisitions: Creating Value Through Corporate Renewal. New York: The Free Press.

Homburg C. and Bucerius ,M (A Marketing perspective on mergers and acquisitions, How marketing integration affects post merger performance

Karim, Samina and Will Mitchell (2000), "Path-Dependent and Path-Breaking Change: Reconfiguring Business Resources Following Acquisitions in the U.S. Medical Sector, 1978-1995," Strategic Management Journal, 21 (10/11), 1061-81.

Krishnan, Hema A. and Daewoo Park (2002), “The Impact of Work Force Reduction on Subsequent Performance in Major Mergers and Acquisitions-An Exploratory Study," Journal of Business Research, 55 (4), 285-92.

Larsson, Rikard (1989), Organizational Integration of Mergers and Acquisitions. Lund: CharwellBratt. 
Larsson, Rikard and Sydney Finkelstein (1999), "Integrating Strategic, Organizational and Human Resource Perspectives on Mergers and Acquisitions: A Case Survey of Synergy Realization," Organization Science, 10 (1), 1-26.

Manne, H.G. (1965). "Mergers and the Market for Corporate Control.” Journal of Political

Economy (April): 110-120.

Marks, Mitchell L. and Philip H. Mirvis (2001), "Making Mergers and Acquisitions Work: Strategic and Psychological Preparation," Academy of Management Executive, 15 (2), 80-92.

Mitchell, D. (1989), "The Importance of Speed in Post-Merger Reorganization," M\&A Europe, 1 (3), 44-48.

Mitra ,S. and Pandey, D. ( 2008). Dynamics of the Merger of Emirates Bank International (EBI) and National Bank of Dubai (NBD)-Strategic Challenges of Regional Consolidation. $8^{\text {th }}$ Global conference on Business and Economics, Italy.ISBN 97809742114-5-9

Ramaswamy , K. (1997) The performance impact of strategic similarity in horizontal mergers: evidence from US banking industry. Academy of management Journal. Vol.40, No: 3, 697-715.

Schweiger, David M. and James P. Walsh (1990), "Mergers and Acquisitions: An Interdisciplinary View," Research in Personnel and Human Resources Management, 8, 41-107.

Schweiger, David M. and Philip K. Goulet (2000), "Integrating Mergers and Acquisitions: An International Research Review," in Advances in Mergers and Acquisitions, C.L. Cooper and A. Gregory, eds. Amsterdam: JAI Press, 61-91.

Shrivastava, Paul (1986), “Post-Merger Integration,” Journal of Business Strategy, 7 (1), 65-76.

Tetenbaum, Toby J. (1999), "Beating the Odds of Merger \&Acquisition Failure: Seven Key Practices that Improve the Chance for Expected Integration and Synergies," Organizational Dynamics, 28 (2), 22-36.

Walsh, James P. (1988), "Top Management Turnover Following Mergers and Acquisitions," Strategic Management Journal, 9 (2), 173-83.

Walsh, James P. (1988), “Top Management Turnover Following Mergers and Acquisitions,” Strategic Management Journal, 9 (2), 173-83. 
Appendix A

QUESTIONS USED FOR THE INTERVIEW

\section{Merger motives}

1. Acquisition or merger motives, increase market share, achieve economies of scale or other???

\section{Communication}

2. Staff integration meetings, announcements, newsletters, mails etc

3. Success and failure stories or errors in communication, mistakes any and how it was corrected.

4. Leader involvement, merger integration team involvement???

5. Amount and quality level of communication that employees received during integration, Types of communication channels used.

\section{Strategic Integration Committees and change management teams}

1. Explain about the formulation, and activities and members of these teams. Was there real project management in the task and human integration process or did you learn through experience how to do the same. Who were the key partners??

\section{Employee retention}

1. What percent of employees were downsized ? Retention data???

2. What percent left voluntarily because of dissatisfaction with their present status after merger from key managerial positions

3. Changes perceived and actual;- about personal situation, job autonomy, level of satisfaction with salary, work environment,

4. Organization outcomes after and before integration in financial terms and other soft measures like customer satisfaction, customer numbers increase, employee satisfaction etc. from secondary data of the company.

\section{Task Integration}

1. Task ambiguity or task specialization what happened during integration

2. Which operational departments were in priority list for quick integration plans. Extent of changes and time taken and speed of change

3. Did the employees share symbiotic relationship on job activities. Did they understand that their work compliments another employee's work and were they ready to join another firm's employee or team in doing work synergically.

4. Were there any parallel practices going on or did the merger lead to an integration of parallel activities. Two departments of each firm doing same function is parallel activity. How the experience and what was was the process and structural changes made???

5. How long did it take for task integration and How did you do it??was there any integration plan, explain the same, was there mile stones, objectives and KPI

6. Was there a lower level of task integration or more integration as planned. What were the integration plans and how did you manage doing the same.

\section{Employee satisfaction with merger}

1. How did the employees consider employees of the other firm. Level of friendliness or hostility. How long did it take to bring it down or is there still some islands of hostility.? 
2. Did the organization measure the disposition or attitude of employees during merger and post merger. Are they satisfied with merger. What are the key concerns they expressed.

3. How did the merger affect employees personal situations. Few examples of role overload or role erosion, etc

4. How much concern and respect they have for the employees of merged organization. Do they have a lack of respect for the new colleagues

5. According to employees which organization got more favorable outcomes of merger

6. Employees and customer perceptions about merger actions, their impact on behavior and organization

7. After the merger which firm's culture predominated the environment. Was there a mix of culture or was there dominance of one culture over other. Explain

8. What level of visibility and continuity of leadership was experienced or perceived by the employees

9. Did some key management personnel leave the organization. Was there any active or passive resistance. How was that managed? Who had dominance in majority of decision making among the two companies.

\section{Merger Management team}

1. Experience level of merger management team

2. Acquisition or merger management team - their names, and any previous experience in mergers or were they new??explain

\section{Leadership Involvement}

3. Leadership visibility and level of involvement in merger activity

4. Explain leadership change. Two CEOs from two different organization??... management of structure, positions and power struggle.

5. Was there two leadership or one after the merger. Any related problems??

6. Did they feel that integration happened smoothly because of consistent leader involvement or do they think more leader involvement was necessary

\section{Brand and image building activities}

7. How was the new logo and brand image communicated., Was that a success. What were the operational activities involved behind that?

\section{Speed, Extent and time of transition}

1. How long did it take for changes to happen and to what extent of human and task integration happened and how far to go from present point. 